\title{
Molecular Control of the Catalytic Properties of Rhodium Nanoparticles in Supported Ionic Liquid Phase (SILP) Systems
}

\author{
Alexis Bordet, Gilles Moos, Calum Welsh, Peter Licence, Kylie L. Luska, and Walter Leitner*
}

Cite This: ACS Catal. 2020, 10, 13904-13912

Read Online

ACCESS |

Wlll Metrics \& More

Article Recommendations

Supporting Information

ABSTRACT: Rhodium nanoparticles (NPs) immobilized on imidazolium-based supported ionic liquid phases (Rh@SILP) act as effective catalysts for the hydrogenation of biomass-derived furfuralacetone. The structure of ionic liquid-type (IL) molecular modifiers was systematically varied regarding spacer, side chain, and anion to assess the influence on the NP synthesis and their catalytic properties. Well-dispersed Rh NPs with diameters in the range of $0.6-2.0 \mathrm{~nm}$ were formed on all SILP materials, whereby the actual size was dependent significantly on the IL structure. The resulting variations in catalytic activity for hydrogenation of the $\mathrm{C}=\mathrm{O}$ moiety in furfuralacetone allowed control of the product selectivity to obtain either the saturated alcohol or the ketone in high yield. Experiments conducted under batch and continuous flow conditions demonstrated that Rh NPs immobilized on SILPs with suitable IL structures are more active and much more stable than $\mathrm{Rh} @ \mathrm{SiO}_{2}$ catalyst synthesized on unmodified silica.

KEYWORDS: supported ionic liquid phases, rhodium nanoparticles, hydrogenation, continuous flow catalysis, biomass

\section{INTRODUCTION}

Ionic liquids (ILs) have found significant interest for the synthesis of metal nanoparticles (NPs) because of their dual role as reaction solvents and NP stabilizers. ${ }^{1,2}$ In particular, imidazolium-based ionic liquids have been used with a broad range of metals because the supramolecular aggregates in these ILs form a protective environment preventing agglomeration. ${ }^{3,4}$ NPs immobilized in ILs (NPs@ILs) have been employed successfully in catalysis as the IL stabilizers allow efficient access for incoming substrates providing a good balance between NP stability and activity. ${ }^{1}$ Due to the intimate contact between the IL and metal NPs, the molecular structure of the IL also plays an important role in defining the morphological (e.g., NP size, shape $)^{5-9}$ and catalytic properties (e.g., activity, selectivity, stability) $)^{10-26}$ of these systems. Thus, the structural diversity of ILs provides a molecular tool by which the properties of NP-based catalysts can be tailored.

The attractive features of ILs have stimulated their use as molecular modifiers for solid materials as catalyst supports. Immobilization of ILs onto porous solids can be accomplished through either physi- or chemisorption, whereby the covalent grafting on silica support has emerged as a very versatile methodology. ${ }^{27,28}$ After incorporation onto solid materials the IL-type modifiers can no longer be considered a true "liquid phase"; nevertheless, these materials are commonly referred to as supported ionic liquid phases (SILPs). SILPs have been shown to be productive supports for metal NPs ${ }^{29}$ (NP@SILP) as they combine the properties of NP@IL catalysts with those of classical supported catalysts including (1) enhanced catalyst stability due to combination of the electrosteric protection of the IL-like layer with the stabilization from the support material and (2) direct implementation into continuous flow processes. $^{30,31}$ NPs@SILP catalysts have been used very successfully in a variety of transformations including $\mathrm{C}-\mathrm{C}$ coupling, hydrogenation, hydrogenolysis, and hydrodeoxygenation under batch and continuous flow conditions. ${ }^{29-41}$ While the influence of the molecular structure of the ILs on the morphology and catalytic properties of metal nanoparticles has been widely studied for the bulk liquid phase, ${ }^{5-26}$ the impact of grafting the IL-type structure covalently on a porous solid is not clear. Understanding how the structure of the IL-like surface functionalities affects the NP synthesis in correlation to the catalytic properties of NP@SILP materials is, however, a prerequisite for the systematic design of these promising catalytic systems. $^{32,34}$

In the present study, we describe the organometallic synthesis of rhodium NPs on a series of imidazolium-based SILPs (Rh@SILP) to assess the influence of the IL-type structural features (anion, alkyl spacer, and $N$-alkyl chain

Received: August 14, 2020

Revised: October 27, 2020 
length) (Figure 1) on the morphology of the NPs and the catalytic properties of the materials. The catalytic hydro-

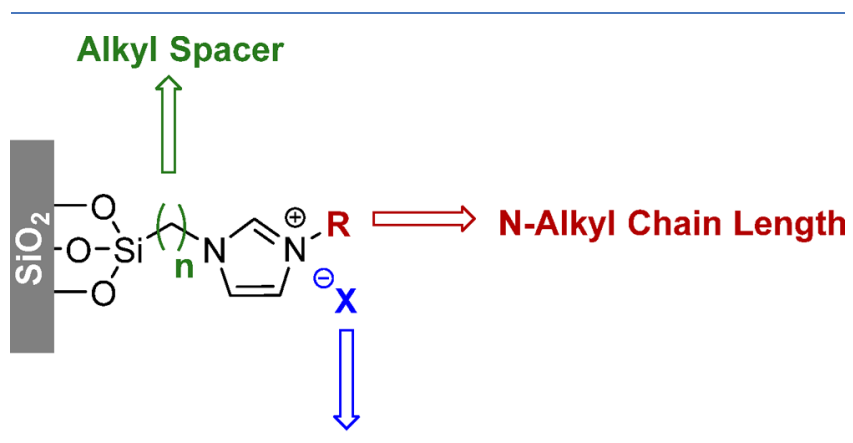

Anion

Figure 1. Schematic representation of the tunable parameters of an imidazolium-based supported ionic liquid phase (SILP) used for the organometallic synthesis of rhodium nanoparticles (Rh@SILP).

genation of biomass-derived furfuralacetone under batch and continuous flow conditions was used as a reactive probe to evaluate the catalytic activities, selectivities, and stabilities in relation to the molecular architecture of the SILP.

\section{RESULTS AND DISCUSSION}

Synthesis and Characterization of Rh@SILP Catalysts. The syntheses of SILPs involved condensation of triethoxysilane-functionalized imidazolium ILs with dehydroxylated silica following an established procedure (see ESI for complete experimental and characterization details). ${ }^{35}$ A material with a neutral $n$-octyl chain grafted on silica ( $\mathrm{Si}-\mathrm{Oct}$ ) was prepared by the same method using $n$-octyltriethoxysilane for comparison. The modularity of the IL precursors allowed for the preparation of a series of silica-based SILPs with systematic variations of the key structural parameters (Figure 2). For the anion, the hydrophobicity was reduced and coordination strength increased for $\mathrm{X}=\mathrm{NTf}_{2}$ (SILP-1) over OTf (SILP-2) to $\mathrm{Br}$ (SILP-3) while keeping the spacer constant at $n=3$ and the side chain $\mathrm{R}=n$-octyl. The alkyl spacer was varied between $n=1$ (SILP-4) and $n=3$ (SILP-1) for the $\mathrm{NTf}_{2}$ anion and the $n$-octyl side chain. The $N$-alkyl side chain was varied in length from $\mathrm{R}=$ methyl (SILP-5) over $n$-butyl (SILP-6) and $n$-octyl
(SILP-1) to $n$-decyl (SILP-7) with the $\mathrm{NTf}_{2}$ anion and the spacer with $n=3$.

Analysis of the SILPs using diffuse reflectance infrared Fourier transform spectroscopy (DRIFTS) showed signals at 3153 and $2940 \mathrm{~cm}^{-1}$ characteristic of the $\mathrm{C}-\mathrm{H}$ stretches of the imidazolium ring and $N$-alkyl chain as well as symmetric ring stretches of the imidazolium moieties at 1569 and $1465 \mathrm{~cm}^{-1}$ (Figure S1). Characterization of the SILPs using $\mathrm{N}_{2}$ adsorption showed the expected decrease in the surface area and pore volume in comparison to starting dehydroxylated $\mathrm{SiO}_{2}$ upon functionalization with the IL precursor (Table 1). The

Table 1. Characterization of the Supports, Including IL Loading and $\mathrm{N}_{2}$ Adsorption Measurements

$\begin{array}{lcccc}\text { support } & \begin{array}{c}\text { IL loading } \\ \left(\mathrm{mmol} \cdot \mathrm{g}^{-1}\right)\end{array} & \begin{array}{c}\text { surface area } \\ \left(\mathrm{BET}, \mathrm{m}^{2} \cdot \mathrm{g}^{-1}\right)\end{array} & \begin{array}{c}\text { pore size } \\ (\mathrm{nm})\end{array} & \begin{array}{c}\text { pore volume } \\ \left(\mathrm{cm}^{3} \cdot \mathrm{g}^{-1}\right)\end{array} \\ \mathrm{SiO}_{2} & & 342.3 & 8.8 & 1.07 \\ \mathrm{Si}-\text { Oct } & 0.40 & 305.1 & 8.1 & 0.94 \\ \text { SILP-1 } & 0.60 & 222.4 & 7.1 & 0.69 \\ \text { SILP-2 } & 0.75 & 209.9 & 7.0 & 0.63 \\ \text { SILP-3 } & 0.68 & 210.5 & 7.3 & 0.66 \\ \text { SILP-4 } & 0.69 & 187.2 & 7.2 & 0.61 \\ \text { SILP-5 } & 0.77 & 225.0 & 7.9 & 0.66 \\ \text { SILP-6 } & 0.70 & 211.0 & 7.4 & 0.68 \\ \text { SILP-7 } & 0.61 & 220.6 & 7.2 & 0.69\end{array}$

decrease was significantly more pronounced for the SILP materials as compared to the modification with the neutral octyl chain in Si-Oct. No significant trends could be derived from variation of the anion or side chain.

Preparation of Rh NPs involved wet impregnation of the SILP (0.5 g) with a solution of the organometallic precursor $\left[\mathrm{Rh}(\text { allyl })_{3}\right]$ (11.3 $\left.\mathrm{mg}, 0.05 \mathrm{mmol}\right)$ in dichloromethane (5 $\mathrm{mL}) .{ }^{36}$ Upon removal of the solvent in vacuo, the impregnated SILP was placed under an atmosphere of $\mathrm{H}_{2}$ (50 bar) at 100 ${ }^{\circ} \mathrm{C}$ for $18 \mathrm{~h}$. During this treatment, the color of the powder changed from light yellow to dark black, indicating formation of nanoparticles to yield Rh@SILP. For comparison, $\mathrm{Rh} @ \mathrm{SiO}_{2}$ on untreated silica and Rh@Si-Oct was also synthesized using the same procedure. Characterization of the Rh@SILPs by ICP-AAS showed a metal loading of $0.8-1.0 \mathrm{wt} \%$, well in agreement with the theoretical value (Table 2). TEM analysis

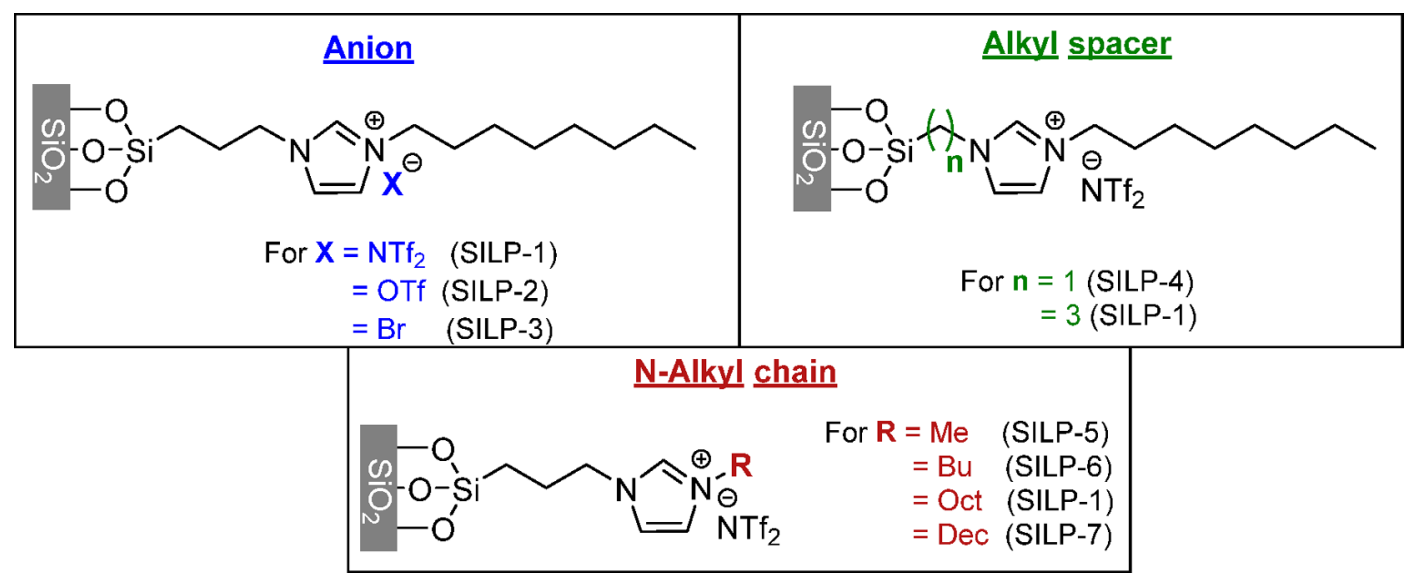

Figure 2. Supported ionic liquid phases (SILPs) prepared to evaluate the influence of the anion, alkyl spacer, and $N$-alkyl chain length on the properties of immobilized rhodium nanoparticles. OTf $=$ trifluoromethanesulfonate and $\mathrm{NTf}_{2}=$ bis(trifluoromethane)sulfonimide. 
evidenced formation of well-dispersed NPs with a narrow size distribution on the different materials (Figure S2 and Table 2).

Table 2. Characterization of the Catalysts, Including Transmission Electron Microscopy (TEM, nanoparticles size distribution) and Inductively Coupled Plasma with Atom-Emission Spectroscopy (ICP-AAS, Rh loading)

\begin{tabular}{lcc}
\multicolumn{1}{c}{ catalyst } & NPs size $(\mathrm{nm})$ & Rh loading $\left(\mathrm{mmol} \cdot \mathrm{g}^{-1}\right)$ \\
Rh@SiO & $1.2 \pm 0.2$ & 0.098 \\
Rh@Si-Oct & $1.1 \pm 0.3$ & 0.083 \\
Rh@SILP-1 & $1.2 \pm 0.3$ & 0.081 \\
Rh@SILP-2 & $1.2 \pm 0.2$ & 0.097 \\
Rh@SILP-3 & $0.6 \pm 0.1$ & 0.088 \\
Rh@SILP-4 & $2.0 \pm 0.4$ & 0.091 \\
Rh@SILP-5 & $0.7 \pm 0.1$ & 0.085 \\
Rh@SILP-6 & $0.9 \pm 0.1$ & 0.084 \\
Rh@SILP-7 & $1.4 \pm 0.2$ & 0.093
\end{tabular}

While Rh NPs synthesized on $\mathrm{SiO}_{2}$ as well as $\mathrm{Si}-$ Oct showed very similar mean diameters of 1.1 and $1.2 \mathrm{~nm}$, respectively, the size of the NPs was significantly influenced by the presence and the nature of the ionic liquid ranging from 0.6 to $2.0 \mathrm{~nm}$. Elongation of the $N$-alkyl side chain from $\mathrm{C} 1(\mathrm{R}=$ Me, SILP-5), over C4 and C8 (n-Bu, SILP-6; $n$-Oct SILP-1), to $\mathrm{C} 10$ ( $n$-Dec, SILP-7) resulted in a progressive increase in the size of the nanoparticles from 0.7 to $1.4 \mathrm{~nm}$. Comparable findings were reported by Basset et al. for the synthesis of $\mathrm{Ru}$ NPs (1.0-2.5 $\mathrm{nm}$ range) in pure imidazolium-based ionic liquids of related structures and identical $\mathrm{NTf}_{2}$ anion. ${ }^{7}$ Reducing the spacer length from 3 carbons (SILP-1) to 1 carbon (SILP-4) also induced a quite significant change in the size of the nanoparticles with the mean diameter increasing from 1.2 to $2.0 \mathrm{~nm}$ (Figure 3). Exchanging the large and weakly coordinating anions $\mathrm{NTf}_{2}{ }^{-}$(SILP-1) and OTf- (SILP2) for small and highly coordinating $\mathrm{Br}^{-}$(SILP-3) also led to a significant decrease in mean diameter to $0.6 \mathrm{~nm}$. Janiak et al. observed similar trends concerning the influence of the anion size on the synthesis of nanoparticles ( $\mathrm{Ag}, \mathrm{Cr}, \mathrm{Mo}$, and W, 3$28 \mathrm{~nm}$ range) in pure imidazolium-based ionic liquids. ${ }^{8,9}$ In summary, while not directly comparable to the effects previously reported for the preparation of NPs in bulk ionic liquids (different metal and/or size range), our results demonstrate that the molecularly modified surfaces resulting from chemisorbed ionic liquid-type structures are able to influence the morphology and, in particular, the size of NPs generated by organometallic methods with similar trends.

XPS characterization was performed to investigate the electronic structures of the SILP and Rh@SILP materials. The results confirm retention of the charge distribution in the IL structures upon grafting and NPs synthesis (Figures S3-S5) and indicate the presence of $\mathrm{Rh}(0)$ and oxidized $\mathrm{Rh}$ centers in the Rh NPs (Figure S6).

The thermal stability of the Rh@SILP materials was evaluated through thermogravimetric analyses performed under $\mathrm{Ar}$ (Figure S7). In all cases, decomposition was associated with a mass loss of $15-20 \%$. The majority of the Rh@SILP materials synthesized were stable up to a temperature range of $330-370{ }^{\circ} \mathrm{C}$ with the exception of Rh@SILP-3 ( $\mathrm{Br}$ as anion), which started to decompose already at $280{ }^{\circ} \mathrm{C}$. No additional trends linking the thermal stability to the structure of the ionic liquid could be identified. These results are fully consistent with previous reports on the thermostability of comparable imidazolium-based ILs supported on silica that showed structural integrity in the range $270-400{ }^{\circ} \mathrm{C}$ with bromide anions resulting in the lowest stability. ${ }^{42,43}$

Evaluation of the Catalytic Properties: Selective Hydrogenation of Furfuralacetone. The catalytic properties of Rh@SILPs were investigated for the hydrogenation of furfuralacetone (1) as a model substrate (Figure 4). Hydrogenation of this biomass-derived substrate provides access to products that are considered as potential fuels and fuel additives. $^{44}$ They are also interesting as chemical building blocks. In the present context, the different functional groups present in this substrate offer the possibility to evaluate variations in the catalytic activity, selectivity, and stability by analysis of the product spectrum as a function of time under batch and continuous flow operation.

The first step of the reaction network consists in the hydrogenation of $\mathrm{C}=\mathrm{C}$ to give 4-(2-furanyl)-2-butanone (2). Then either the furan ring is hydrogenated first, giving the saturated ketone 4-(tetrahydro-2-furanyl)-2-butanone (3) through route a, or the ketone is hydrogenated first, giving the unsaturated alcohol $\alpha$-methyl-2-furanpropanol (4) through route b. Finally, 3 and 4 are hydrogenated to form the completely saturated tetrahydro- $\alpha$-methyl-2-furanpropanol
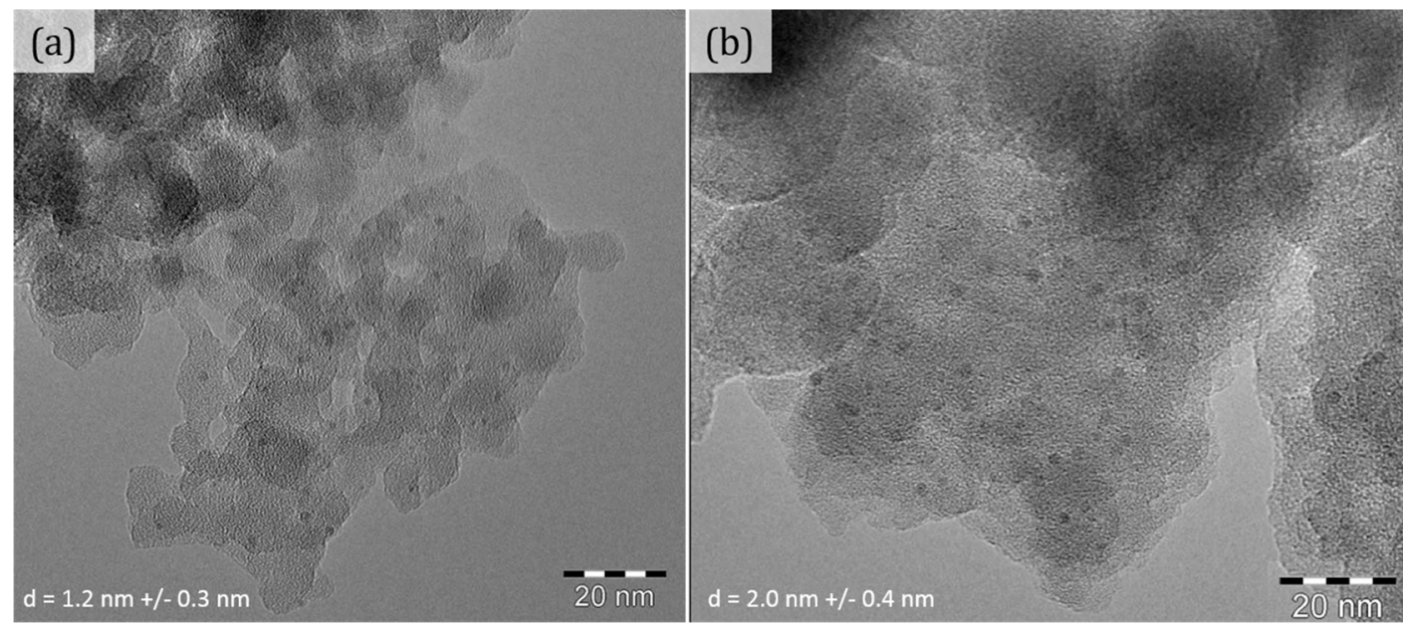

Figure 3. Transmission electron microscopy analysis of (a) Rh@SILP-1 and (b) Rh@SILP-4. 


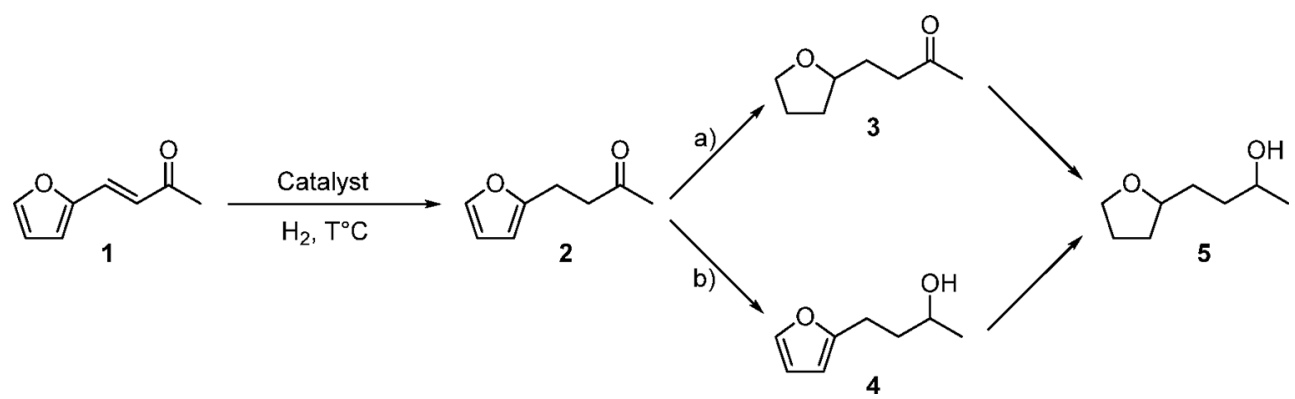

Figure 4. Hydrogenation network of furfuralacetone (1).

Table 3. Hydrogenation of Furfuralacetone Using Rh NPs Immobilized on Various Supports ${ }^{a}$

\begin{tabular}{|c|c|c|c|c|c|c|}
\hline \multirow[b]{2}{*}{ Time } & \multirow[b]{2}{*}{ Support } & \multirow[b]{2}{*}{$\begin{array}{c}\text { NPs size } \\
(\mathrm{nm})\end{array}$} & \multicolumn{4}{|c|}{ Product yield $(\%)^{\mathrm{b}} / \operatorname{TOF}\left(h^{-1}\right)^{\mathrm{c}}$} \\
\hline & & & & & & \\
\hline \multirow{3}{*}{$1 \mathrm{~h}$} & $\mathrm{SiO}_{2}$ & 1.2 & 0 & 80 & 2 & $18 / 34$ \\
\hline & Si-Oct & 1.1 & 0 & 64 & 3 & $33 / 58$ \\
\hline & SILP-1 & 1.2 & 0 & 32 & 0 & $68 / 127$ \\
\hline \multirow{3}{*}{$18 \mathrm{~h}$} & $\mathrm{SiO}_{2}$ & 1.2 & 0 & 30 & 3 & 67 \\
\hline & Si-Oct & 1.1 & 0 & 0 & 4 & 96 \\
\hline & SILP-1 & 1.2 & 0 & 1 & 0 & 99 \\
\hline
\end{tabular}

${ }^{a}$ Reaction conditions: Rh@SILP (40 mg, $0.004 \mathrm{mmol}$ total metal loading), heptane $(0.5 \mathrm{~mL})$, furfuralacetone $(0.4 \mathrm{mmol}, 100 \mathrm{equiv}), \mathrm{H}_{2}(20 \mathrm{bar})$, $100{ }^{\circ} \mathrm{C}$. ${ }^{b}$ Determined by GC using tetradecane as an internal standard. The conversion is $100 \%$ in all cases. ${ }^{c}$ Calculated based on the estimated percentage of Rh atoms at the surface of the NPs, see SI and Table S1 for details.

Table 4. Hydrogenation of Furfuralacetone Using Rh@SILP with Different Anions ${ }^{a}$

\begin{tabular}{|c|c|c|c|c|c|c|c|}
\hline \multirow[b]{2}{*}{ Time } & \multirow[b]{2}{*}{ Support } & \multirow[b]{2}{*}{ Anion } & \multirow[b]{2}{*}{$\begin{array}{c}\text { NPs size } \\
(\mathrm{nm})\end{array}$} & \multicolumn{4}{|c|}{ Product yield $(\%)^{\mathrm{b}} /$ TOF $\left(h^{-1}\right)^{\mathrm{c}}$} \\
\hline & & & & & & & \\
\hline \multirow{4}{*}{$1 \mathrm{~h}$} & $\mathrm{SiO}_{2}$ & - & 1.2 & 0 & 80 & 2 & $18 / 34$ \\
\hline & SILP-1 & $\mathrm{NTf}_{2}$ & 1.2 & 0 & 32 & 0 & $68 / 127$ \\
\hline & SILP-2 & OTf & 1.2 & 0 & 97 & 0 & $3 / 5$ \\
\hline & SILP-3 & $\mathrm{Br}$ & 0.6 & 0 & 89 & 0 & $11 / 13$ \\
\hline \multirow{4}{*}{$18 \mathrm{~h}$} & $\mathrm{SiO}_{2}$ & - & 1.2 & 0 & 30 & 3 & 67 \\
\hline & SILP-1 & $\mathrm{NTf}_{2}$ & 1.2 & 0 & 1 & 0 & 99 \\
\hline & SILP-2 & OTf & 1.2 & 0 & 85 & 0 & 15 \\
\hline & SILP-3 & $\mathrm{Br}$ & 0.6 & 0 & 61 & 0 & 39 \\
\hline
\end{tabular}

${ }^{a}$ Reaction conditions: Rh@SILP (40 mg, $0.004 \mathrm{mmol}$ total metal loading), heptane ( $\left.0.5 \mathrm{~mL}\right)$, furfuralacetone $(0.4 \mathrm{mmol}, 100 \mathrm{equiv}), \mathrm{H}_{2}(20 \mathrm{bar})$, $100{ }^{\circ} \mathrm{C}$. ${ }^{b}$ Determined by GC using tetradecane as an internal standard. The conversion is $100 \%$ in all cases. ${ }^{c}$ Calculated based on the estimated percentage of Rh atoms at the surface of the NPs, see SI and Table S1 for details.

(5). Noble metal catalysts typically follow pathway a and generally lead to the deep hydrogenation product 5 as the main product. While deoxygenation of the secondary alcohol and ring opening are also possible with NPs in ILs or on SILPs, these consecutive reactions starting from 5 require multifunctional systems comprising acidic co-catalysts ${ }^{30,35,38}$ and are not relevant for this study.

The catalytic performance of Rh@SILPs catalysts was investigated in batch conditions using magnetically stirred high-pressure reactors $(10 \mathrm{~mL}$, stainless steel) in heating cones under controlled conditions. In typical experiments, furfuralacetone ( $54.5 \mathrm{mg} ; 0.40 \mathrm{mmol} ; 100$ equiv) was dissolved in heptane $(0.5 \mathrm{~mL})$ and reacted in the presence of the catalyst (40.0 mg; $0.004 \mathrm{mmol}$ of $\mathrm{Rh}$ ) under $\mathrm{H}_{2}\left(20 \mathrm{bar}\right.$ ) at $100{ }^{\circ} \mathrm{C}$.

A first objective consisted in investigating the use of the imidazolium-type molecular modifiers in SILPs as compared to conventional support materials. Therefore, the catalytic properties of Rh@SILP-1, Rh@SiO ${ }_{2}$, and Rh@Si-Oct were examined for hydrogenation of furfuralacetone after 1 and $18 \mathrm{~h}$ reaction times (Table 3 ).

While the three catalysts contain Rh NPs of similar sizes, Rh@SILP-1 was found to be more effective than $\mathrm{Rh@SiO}$ and Rh@Si-Oct for complete hydrogenation of $\mathbf{1}$ to product 5 ( $68 \%$ yield after $1 \mathrm{~h}, 99 \%$ after $18 \mathrm{~h}$ ). On the basis of the estimated surface $\mathrm{Rh}$ atoms, this corresponds to a much higher turnover frequency (TOF) for product formation. Considering the necessary hydrogenation events ( 1 to reach 2, 3 for 3, and 4 for 5), the difference is even more pronounced. In all cases, the saturated ketone 3 was observed as the main intermediate, confirming that pathway a is favored on Rh NPs as expected. These results indicate that $\mathrm{Rh}$ NPs immobilized on SILP-1 exhibit superior catalytic activity compared to those immobi- 
Table 5. Hydrogenation of Furfuralacetone Using Rh@SILP with Different $N$-Alkyl Chains ${ }^{a}$

\begin{tabular}{|c|c|c|c|c|c|c|c|}
\hline \multirow[b]{2}{*}{ Time } & \multirow[b]{2}{*}{ Support } & \multirow[b]{2}{*}{$\mathrm{R}$} & \multirow[b]{2}{*}{$\begin{array}{l}\text { NPs size } \\
(\mathrm{nm})\end{array}$} & \multicolumn{4}{|c|}{ Product yield $(\%)^{\mathrm{b}} / \mathrm{TOF}\left(h^{-1}\right)^{\mathrm{c}}$} \\
\hline & & & & & & & \\
\hline \multirow{5}{*}{$1 \mathrm{~h}$} & $\mathrm{SiO}_{2}$ & - & 1.2 & 0 & 80 & 2 & $18 / 34$ \\
\hline & SILP-5 & $\mathrm{Me}$ & 0.7 & 0 & 87 & 1 & $12 / 16$ \\
\hline & SILP-6 & $\mathrm{Bu}$ & 0.9 & 0 & 72 & 0 & $28 / 43$ \\
\hline & SILP-1 & Oct & 1.2 & 0 & 32 & 0 & $68 / 127$ \\
\hline & SILP-7 & Dec & 1.4 & 0 & 68 & 2 & $30 / 63$ \\
\hline \multirow{5}{*}{$18 \mathrm{~h}$} & $\mathrm{SiO}_{2}$ & - & 1.2 & 0 & 30 & 3 & 67 \\
\hline & SILP-5 & $\mathrm{Me}$ & 0.7 & 0 & 15 & 1 & 84 \\
\hline & SILP-6 & $\mathrm{Bu}$ & 0.9 & 0 & 1 & 0 & 99 \\
\hline & SILP-1 & Oct & 1.2 & 0 & 1 & 0 & 99 \\
\hline & SILP-7 & Dec & 1.4 & 0 & 1 & 0 & 99 \\
\hline
\end{tabular}

${ }^{a}$ Reaction conditions: Rh@SILP (40 mg, $0.004 \mathrm{mmol}$ total metal loading), heptane $(0.5 \mathrm{~mL})$, furfuralacetone $(0.4 \mathrm{mmol}, 100 \mathrm{equiv}), \mathrm{H}_{2}(20 \mathrm{bar})$, $100{ }^{\circ} \mathrm{C}$. ${ }^{b}$ Determined by GC using tetradecane as an internal standard. The conversion is $100 \%$ in all cases. ${ }^{c}$ Calculated based on the estimated percentage of Rh atoms at the surface of the NPs, see SI and Table S1 for details.

lized on $\mathrm{SiO}_{2}$ and $\mathrm{Si}-\mathrm{Oct}$, in particular with respect to the ketone hydrogenation step $3 / 5$. This point being clarified, the influence of structural changes in SILPs on the catalytic properties of Rh NPs was investigated. The results obtained with $\mathrm{Rh}$ nanoparticles supported on $\mathrm{SiO}_{2}$ (without ionic liquid) are systematically given as a reference (Tables 4-6).

We first studied the influence of the nature of the anion on the catalytic properties of Rh@SILP materials (Table 4). Using OTf or Br as anions in Rh@SILP-2 and Rh@SILP-3 led to mixtures of $\mathbf{3}$ and $\mathbf{5}$ after $1 \mathrm{~h}$ with the saturated ketone $\mathbf{3}$ as the main product ( $98 \%$ and $89 \%$ yield, respectively). In contrast, $\mathbf{5}$ was obtained as the major product (68\%) using Rh@SILP-1 corresponding to a much higher TOF of product formation per surface Rh atom than for Rh@SILP-2 and Rh@SILP-3. This trend was confirmed after $18 \mathrm{~h}$ reaction time, where only Rh@ SILP-1 achieved nearly quantitative formation of $\mathbf{5}$. Given the rather slow hydrogenation of $\mathbf{3}$ to $\mathbf{5}$ with Rh@SILP-2 (only $12 \%$ conversion in $17 \mathrm{~h}$ ), this catalyst can be in fact considered quite selective for $\mathrm{C}=\mathrm{C}$ vs $\mathrm{C}=\mathrm{O}$ hydrogenation in substrate 1. Use of the largest and most weakly coordinating anion $\left(\mathrm{NTf}_{2}\right)$ was found to be highly beneficial to achieve full hydrogenation of furfuralacetone. This is consistent with previous studies involving metal NPs in bulk ionic liquids for hydrogenation reactions. ${ }^{45}$ Concluding that the $\mathrm{NTf}_{2}$ anion exhibits the weakest interaction with the NPs, it was used in all materials for the rest of the study.

In the next step, the influence of the length of the $N$-alkyl chain was investigated (Table 5). For a reaction time fixed to 1 $\mathrm{h}$, the increase in the $N$-alkyl chain length $(\mathrm{Me} \rightarrow \mathrm{Bu} \rightarrow \mathrm{Oct})$ associated with the increase in NPs size $(0.7 \rightarrow 0.9 \rightarrow 1.2 \mathrm{~nm})$ resulted in an increase in the yield of 5 and the corresponding TOFs. Increasing the $N$-alkyl chain length (Dec) further gave a substantially lower yield of $\mathbf{5}$ and TOF despite the continuing growth of the particle size. After 18 h, Rh@SILP-6, 1, and 7 led to quantitative yields of 5, while Rh@SILP-5 still gave a mixture of 3 and $\mathbf{5}$. These results suggest a significant NPs size effect with a size of $1.2 \mathrm{~nm}$ displaying optimal catalytic activity for complete hydrogenation of furfuralacetone to $\mathbf{5}$. Again, it appears that the ketone hydrogenation step is influenced most strongly, albeit far less than through the anion variation.

The influence of the distance between the cationic head group of the ionic liquid and the support was studied by decreasing the length of the spacer from 3 carbons (SILP-1) to 1 carbon atom (SILP-4) while keeping the $\mathrm{NTf}_{2}$ anion and the $N$-octyl chain (Table 6). In the case of Rh@SILP-4 (C1

Table 6. Hydrogenation of Furfuralacetone Using Rh@SILP with Different Spacer Lengths ${ }^{a}$

\begin{tabular}{|c|c|c|c|c|c|c|c|}
\hline \multirow[b]{2}{*}{ Time } & \multirow[b]{2}{*}{ Support } & \multirow[b]{2}{*}{$\mathrm{n}$} & \multirow[b]{2}{*}{$\begin{array}{l}\text { NPs } \\
\text { size } \\
(\mathrm{nm})\end{array}$} & \multicolumn{4}{|c|}{ Product distribution $(\%)^{b}$} \\
\hline & & & & & & & 5 \\
\hline \multirow{3}{*}{$18 \mathrm{~h}$} & $\mathrm{SiO}_{2}$ & - & 1.2 & 0 & 30 & 3 & 67 \\
\hline & SILP-1 & 3 & 1.2 & 0 & 1 & 0 & 99 \\
\hline & SILP-4 & 1 & 2.0 & 0 & 97 & 0 & 3 \\
\hline $1 \mathrm{~h}$ & SILP-4 & 1 & 2.0 & 0 & 98 & 0 & 2 \\
\hline $28 \mathrm{~h}$ & SILP-4 & 1 & 2.0 & 0 & 95 & 0 & 5 \\
\hline
\end{tabular}

${ }^{a}$ Reaction conditions: Rh@SILP (40 mg, $0.004 \mathrm{mmol}$ total metal loading), heptane $(0.5 \mathrm{~mL})$, furfuralacetone $(0.4 \mathrm{mmol}, 100$ equiv), $\mathrm{H}_{2}$ (20 bar), $100{ }^{\circ} \mathrm{C}$. ${ }^{b}$ Determined by GC using tetradecane as an internal standard. The conversion is $100 \%$ in all cases.

spacer), $97 \%$ of 3 was obtained even after $18 \mathrm{~h}$ reaction time, suggesting a strongly suppressed ketone hydrogenation. Complementary experiments performed with shorter $(1 \mathrm{~h})$ and longer $(28 \mathrm{~h})$ reaction times showed that the conversion of 1 to 3 involving $\mathrm{C}=\mathrm{C}$ hydrogenation is very fast while the $\mathrm{C}=\mathrm{O}$ hydrogenation of $\mathbf{3}$ to $\mathbf{5}$ is essentially shut down. Time profiles of furfuralacetone hydrogenation over Rh@SILP-1 and Rh@SILP-4 were recorded in order to bring further insight into their reactivity (Figure 5). Using Rh@SILP-1, furfuralacetone was very quickly $(\sim 1 \mathrm{~h})$ converted to the saturated ketone 3, which was then consumed over time to give a quantitative yield of 5 after $8 \mathrm{~h}$ in a typical kinetic profile for sequential reaction steps.

Hydrogenation of the aliphatic and aromatic $\mathrm{C}=\mathrm{C}$ double bonds over Rh@SILP-1 was so fast that no significant concentration of the intermediate 2 was built up. The rate of the final $\mathrm{C}=\mathrm{O}$ hydrogenation in compound 3 can be determined as $0.204 \mathrm{M} \cdot \mathrm{h}^{-1}$, corresponding to a TOF for this last step of $187 \mathrm{~h}^{-1}$. The TOF for the overall formation of product 5 is estimated as $159 \mathrm{~h}^{-1}$ under these conditions, confirming that it is almost completely determined by the $\mathrm{C}=$ O hydrogenation rate. In contrast, a mixture of $\mathbf{2}$ and 3 (29\% and $70 \%$, respectively) was observed after $1 \mathrm{~h}$ reaction when 
(a)

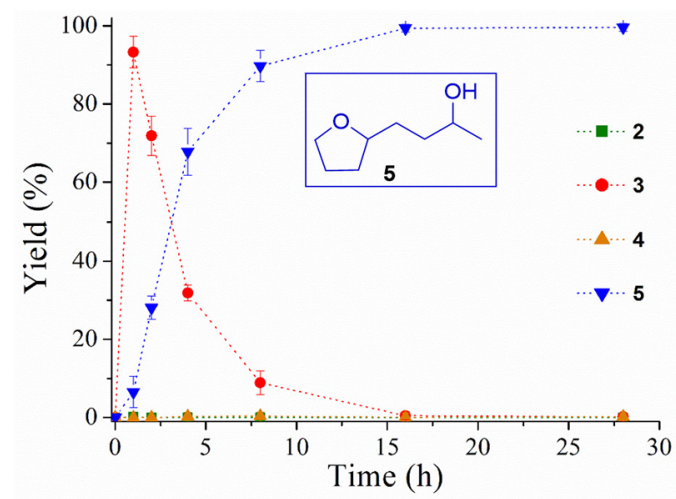

(b)

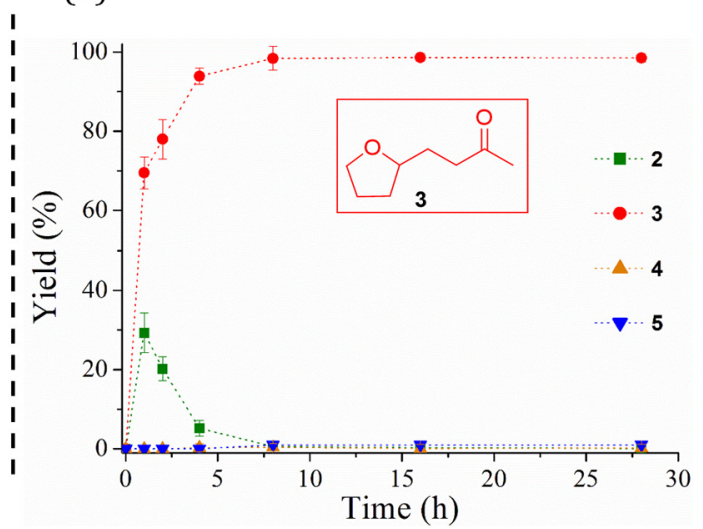

Figure 5. Reaction time profile for the hydrogenation of furfuralacetone using (a) Rh@SILP-1 and (b) Rh@SILP-4. Reaction conditions: Rh@ SILP $(10 \mathrm{mg}, 0.001 \mathrm{mmol}$ of $\mathrm{Rh})$, furfuralacetone $\left(68.0 \mathrm{mg}, 0.5 \mathrm{mmol}, 500\right.$ equiv), heptane $(0.5 \mathrm{~mL})(20 \mathrm{bar}), 100^{\circ} \mathrm{C}$. Error bars represent the variations from three independent experiments.

Rh@SILP-4 was used as catalyst. In this case, hydrogenation of the heteroaromatic ring is significantly slower than that with Rh@SILP-1 but still occurs with an estimated rate of $0.695 \mathrm{M}$ $\mathrm{h}^{-1}$ and TOF of $992 \mathrm{~h}^{-1}$. After $4 \mathrm{~h}, 2$ was completely converted to the saturated ketone 3 , which was not further hydrogenated to 5 even after a reaction time of $28 \mathrm{~h}$, confirming the exceptional selectivity of the $C_{1}$ spacer catalyst Rh@SILP-4 accessing product 3 in nearly quantitative yield.

Notably, the large difference in catalytic performance upon reducing the size of the alkyl spacer from three carbons in Rh@SILP-1 to one carbon in Rh@SILP-4 is corroborated again with a significant increase of the NPs size from 1.2 to 2.0 $\mathrm{nm}$. This observation is consistent with the trend shown in Table 5, where the activity of Rh NPs for the overall transformation $\mathbf{1} \rightarrow \mathbf{5}$ increases with their size until reaching a maximum at $1.2 \mathrm{~nm}$ and then decreases for larger NPs. The corroboration between particle size and catalyst performance is illustrated via the estimated TOF values for the overall product 5 formation in Figure 6. The product composition at different
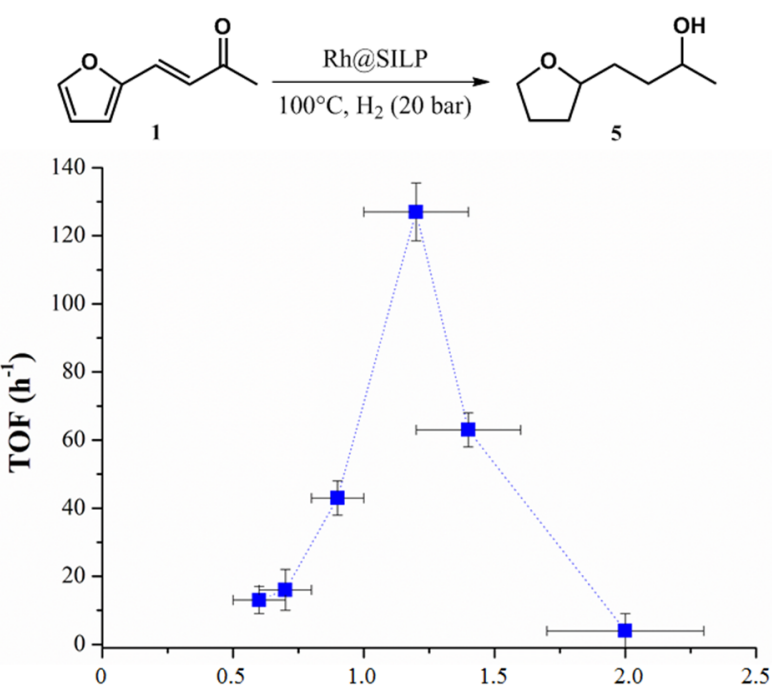

Figure 6. Nanoparticles size effect in the hydrogenation of 1 to 5 using Rh@SILP catalysts. TOFs calculated based on the estimated percentage of Rh atoms at the surface of the NPs, see SI and Table S1 for details. time intervals indicates that this trend reflects largely the $\mathrm{C}=$ $\mathrm{O}$ hydrogenation activity, which ultimately becomes almost negligible for the $2 \mathrm{~nm}$ NPs in Rh@SILP-4 under these conditions. Nevertheless, further insight will be required to distinguish whether the change in $\mathrm{C}=\mathrm{O}$ hydrogenation activity is reflecting a preferred activation of the functional group or a different mode of activation for $\mathrm{H}_{2}$ (homolytic vs heterolytic) or even a combination of the two.

Huan and co-workers reported similar effects when using supported $\mathrm{Ru}$ NPs for hydrogenation of aromatic ketones. ${ }^{46}$ The authors observed low activity for NPs below $4 \mathrm{~nm}$ and then increasing TOFs when increasing the size of the Ru NPs up to 5-6 $\mathrm{nm}$ followed by a drop of activity for larger NPs. The influence of the SILP structure observed with Rh NPs in the present study follows the same trend, albeit centered on a much smaller "optimal" size and with more marked drops of activity at lower and larger NPs sizes.

While NPs size effects on ketone hydrogenation have been scarcely described in the literature, ${ }^{46}$ the study of furfuralacetone hydrogenation under batch conditions evidenced a clear influence of the ionic liquid-type modifier in the SILP materials on the catalytic properties of the Rh@SILP systems. Two distinct selectivities were identified for the Rh@SILP catalysts leading to effective formation of either the deep hydrogenation product 5(Rh@SILP-1) or the saturated ketone 3 (Rh@SILP-4). The activity, selectivity, and stability of these catalysts were further investigated under continuous flow conditions and compared directly to the materials on more conventional supports $\mathrm{Rh} @ \mathrm{SiO}_{2}$ and $\mathrm{Rh} @ \mathrm{Si}-\mathrm{Oct}$ (Figure 7). Experimentally, a solution of furfuralacetone (0.05 $\mathrm{M}$ in heptane) was passed over a cartridge packed with the Rh-based catalysts using a $\mathrm{H}$-Cube Pro reactor system at a substrate flow rate of $0.5 \mathrm{~mL} \cdot \mathrm{min}^{-1}$ (residence time $=2.00$ min). The temperature and $\mathrm{H}_{2}$ pressure applied were similar to what was used for batch reactions, i.e., $100{ }^{\circ} \mathrm{C}$ and $20 \mathrm{bar} \mathrm{H}_{2}$ $\left(35 \mathrm{~mL} \cdot \mathrm{min}^{-1}\right)$.

The $\mathrm{Rh} @ \mathrm{SiO}_{2}$ and $\mathrm{Rh} @ \mathrm{Si}-\mathrm{Oct}$ showed a very similar behavior, indicating rapid changes of the catalytic properties over time. The catalyst with unmodified silica as support showed a high initial activity and selectivity toward formation of the completely saturated product 5 (Figure $7 \mathrm{a}$ ). However, the product distribution changed drastically within a few hours on stream ( $70 \%$ of 3 and $30 \%$ of 2 after 6 h), evidencing a 
(a)

(b)
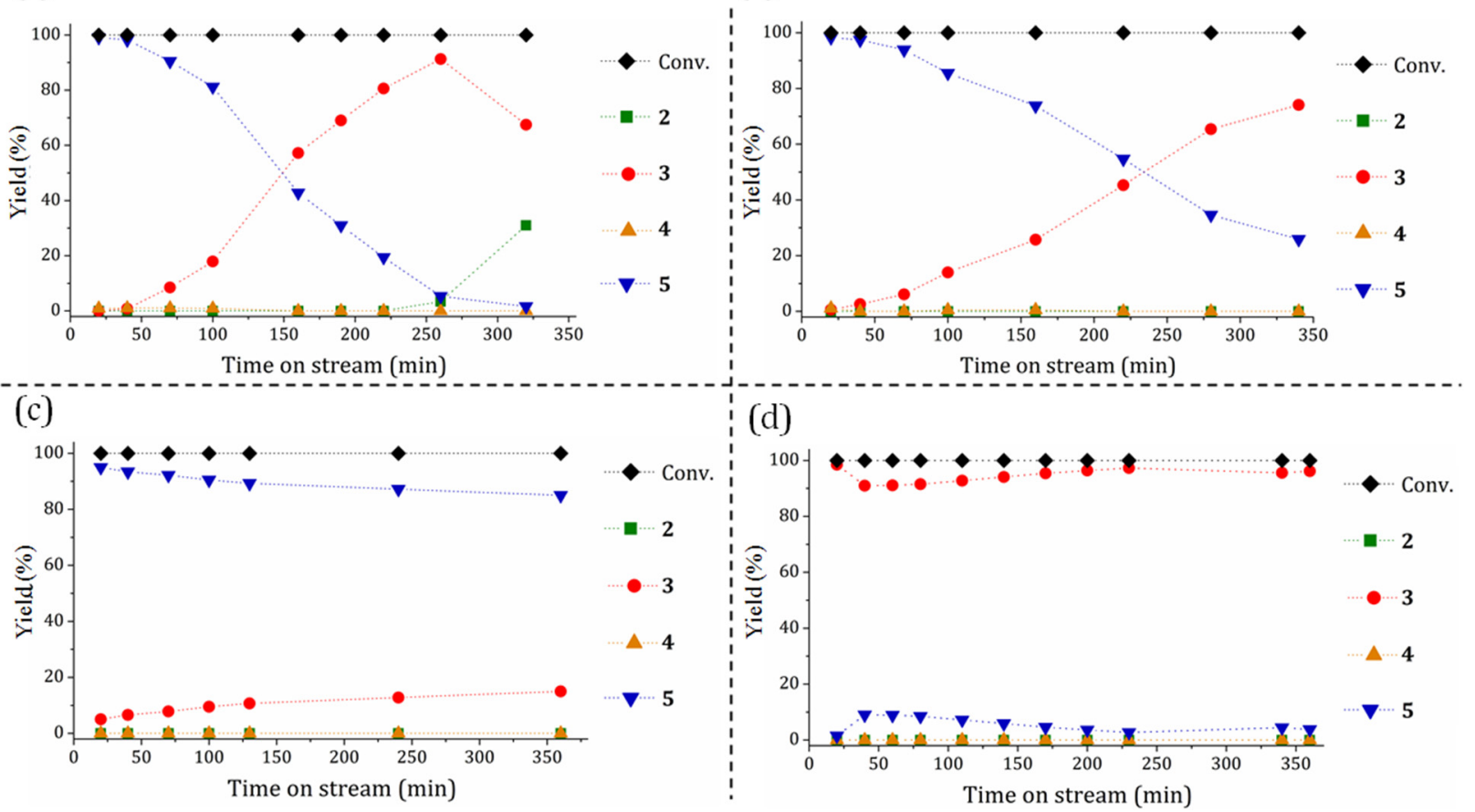

(d)
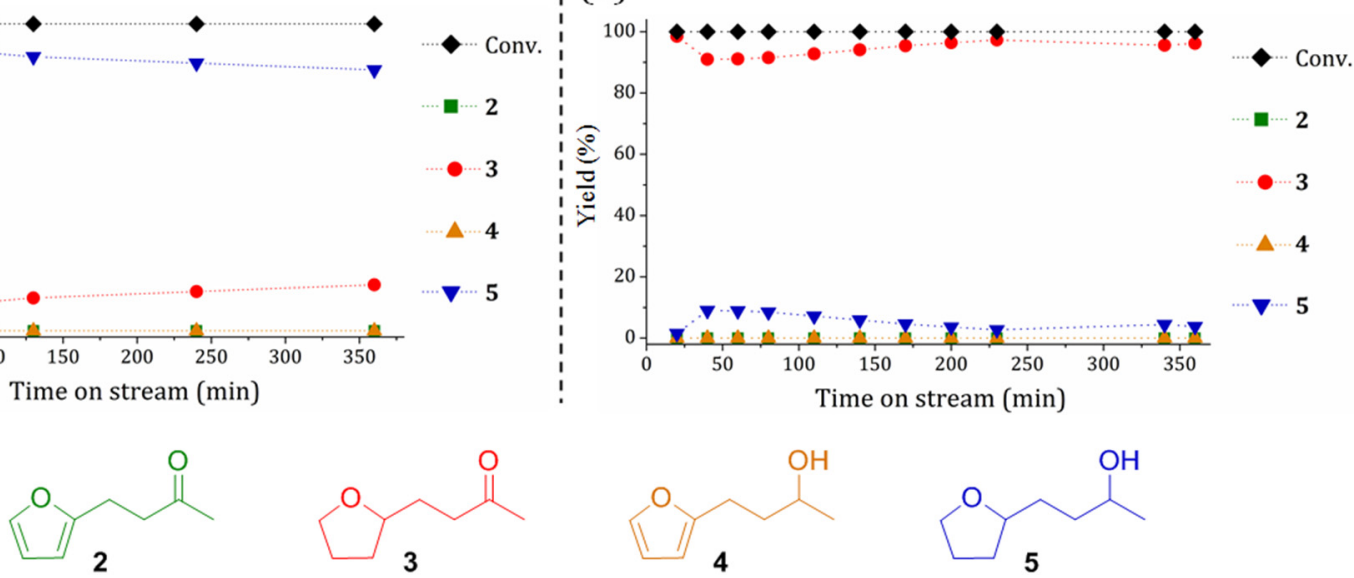

Figure 7. Hydrogenation of furfuralacetone $\left(0.05 \mathrm{M}\right.$ in heptane, $\left.0.5 \mathrm{~mL} \cdot \mathrm{min}^{-1}\right)$ using different $\mathrm{Rh}$-based catalysts $(200 \mathrm{mg}, 0.02 \mathrm{mmol} \mathrm{Rh}) \mathrm{under}$ continuous flow conditions at $100{ }^{\circ} \mathrm{C}$ and 20 bar $\mathrm{H}_{2}$ (gas flow rate $=35 \mathrm{~N} \mathrm{~mL} \cdot \mathrm{min}^{-1}$ ): (a) Rh@SiO 2 , (b) Rh@Si-Oct, (c) Rh@SILP-1, and (d) Rh@SILP-4.

strong loss of catalytic activity with time. Using the n-octylcapped silica resulted in a largely comparable performance, albeit the deactivation process was slightly slower (Figure $7 \mathrm{~b}$ ). While ICP-AAS measurements did not show any significant change in the $\mathrm{Rh}$ content of these catalysts, BET and TEM analyses evidenced a clear decrease of the surface area and increase of the NPs size after $6 \mathrm{~h}$ on stream (Table S2 and Figure S10). The increase of the Rh NPs size observed for the reference catalysts under catalytic conditions (from 1.2 to 2.3 on the $\mathrm{SiO}_{2}$ support and from 1.1 to 2.1 on the $\mathrm{Si}-\mathrm{Oct}$ support) is a well-known deactivation process for supported nanoparticles reflecting sintering and/or Ostwald ripening. ${ }^{47,48}$ In agreement with the NPs size effect highlighted in Figure 6, the progressive growth of the NPs corroborates with the decreasing yield of $\mathbf{5}$ over time.

In sharp contrast, the SILP materials containing the imidazolium-based surface modifiers retained their initial performance in a much more stable way. Using Rh@SILP-1 in continuous flow conditions led to formation of the deep hydrogenation product $\mathbf{5}$ with high activity throughout the full time on stream (Figure 7c), showing only a slight decrease of selectivity with time (yield of 5 decreased from $95 \%$ to $85 \%$ after $6 \mathrm{~h}$ ). In agreement with what was observed under batch conditions, the catalytic hydrogenation of furfuralacetone using Rh@SILP-4 in continuous flow conditions led to selective formation of the saturated ketone 3 in high yield (Figure $7 d$ ). The performance of Rh@SILP-4 was found to be very stable with a yield of 3 higher than $90 \%$ with only minor variations over the $6 \mathrm{~h}$ time on stream. ICP-AAS and IR analyses of the used catalysts did not evidence any leaching or structural changes of the ionic liquids after catalysis in continuous flow conditions (Table S2 and Figure S8). In addition, TEM, ICPAAS, and BET showed that the NPs size, Rh loading, and surface area of Rh@SILP-1 and Rh@SILP-4 did not change significantly, further evidencing the increased stability imposed by the SILP materials as compared to the conventional supports (Table S2 and Figure S9).

Additional experiments performed at a higher flow rate (1.0 $\mathrm{mL} \cdot \mathrm{min}^{-1}$ ) led to a lower yield of $3(20 \%)$, which only decreased to $17 \%$ after ca. $4 \mathrm{~h}$ on stream, thus confirming the catalyst's very good stability (Figure S10).

\section{CONCLUSION}

The synthesis, characterization, and catalytic evaluation of rhodium nanoparticles (NPs) immobilized on a systematic set of imidazolium-based supported ionic liquid phases (Rh@ SILP) provided insight into the potential control factors offered by the IL-type surface modifiers on the performance of the materials in catalysis. The molecularly defined SILP materials were found to lead to significantly more active and stable systems as compared to unmodified or simple alkylcapped silica materials in the catalytic hydrogenation of furfuralacetone as a reactive probe. Systematic variation of the molecular structure (anion, spacer length, $N$-alkyl chain length) of the ionic liquid-type molecular modifier at the silica surface was demonstrated to influence the morphology of the synthesized nanoparticles with trends comparable to what has been reported in bulk ionic liquids. This indicates that the chemisorption of ionic liquids on solid supports does not significantly deprive them of their ability to control nano- 
particle formation despite the fact that the same supramolecular aggregates as in the liquid phase cannot be formed on the surface layer.

While additional effects from the direct NP-SILP interaction cannot be excluded, control of the NP size during organometallic preparation seems to corroborate directly with the catalytic performance in particular regarding the $\mathrm{C}=\mathrm{O}$ hydrogenation. It is currently impossible to distinguish whether the IL influences both size and activity or whether the size effect causes the change in reactivity. Further research will be required to resolve this "hen-and-egg" problem. Nevertheless, the systematic trends can be used as guidelines in the rational design of catalysts with specific reactivity, as demonstrated here for selective production of either the saturated alcohol or the ketone as the target product for furfuralacetone hydrogenation.

\section{- ASSOCIATED CONTENT}

\section{SI Supporting Information}

The Supporting Information is available free of charge at https://pubs.acs.org/doi/10.1021/acscatal.0c03559.

Complete synthesis, characterization, and catalysis data for ionic liquids, SILPs, Rh@SiO 2 , Rh@Si-Oct, and Rh@SILP materials (PDF)

\section{AUTHOR INFORMATION}

\section{Corresponding Author}

Walter Leitner - Max Planck Institute for Chemical Energy Conversion, Mülheim an der Ruhr 45470, Germany; Institut für Technische und Makromolekulare Chemie, RWTH Aachen University, Aachen 52074, Germany; (1) orcid.org/ 0000-0001-6100-9656; Phone: (+49) 241-80-26481; Email: walter.leitner@cec.mpg.de; Fax: (+49) 241-8022177

\section{Authors}

Alexis Bordet - Max Planck Institute for Chemical Energy Conversion, Mülheim an der Ruhr 45470, Germany; (1) orcid.org/0000-0003-0133-3416

Gilles Moos - Max Planck Institute for Chemical Energy Conversion, Mülheim an der Ruhr 45470, Germany; Institut für Technische und Makromolekulare Chemie, RWTH Aachen University, Aachen 52074, Germany

Calum Welsh - The University of Nottingham, School of Chemistry, Nottingham NG7 2RD, United Kingdom

Peter Licence - The University of Nottingham, School of Chemistry, Nottingham NG7 2RD, United Kingdom; (i) orcid.org/0000-0003-2992-0153

Kylie L. Luska - Institut für Technische und Makromolekulare Chemie, RWTH Aachen University, Aachen 52074, Germany

Complete contact information is available at: https://pubs.acs.org/10.1021/acscatal.0c03559

\section{Notes}

The authors declare no competing financial interest.

\section{ACKNOWLEDGMENTS}

The authors acknowledge financial support by the Max Planck Society and by the Deutsche Forschungsgemeinschaft (DFG, German Research Foundation) under Germany's Excellence Strategy-Exzellenzcluster 2186 "The Fuel Science Center” ID: 390919832. We thank Karl-Josef Vaeßen (ITMC, RWTH
Aachen University) for $\mathrm{N}_{2}(\mathrm{~g})$ adsorption measurements, Heike Bergstein (ITMC, RWTH Aachen University) for ICP measurements, Bernd Spliethoff (Max-Planck-Institut für Kohlenforschung) for TEM analysis, and Marius Podleska (Max Planck Institute for Chemical Energy Conversion) for TGA measurements.

\section{REFERENCES}

(1) Dupont, J.; Scholten, J. D. On the Structural and Surface Properties of Transition-Metal Nanoparticles in Ionic Liquids. Chem. Soc. Rev. 2010, 39, 1780-1804.

(2) Prechtl, M. H. G. Nanocatalysis in Ionic Liquids; Wiley-VCH: Weinheim, 2017.

(3) Fonseca, G. S.; Machado, G.; Teixeira, S. R.; Fecher, G. H.; Morais, J.; Alves, M. C. M.; Dupont, J. Synthesis and Characterization of Catalytic Iridium Nanoparticles in Imidazolium Ionic Liquids. J. Colloid Interface Sci. 2006, 301, 193-204.

(4) Pensado, A. S.; Padua, A. A. H. Solvation and Stabilization of Metallic Nanoparticles in Ionic Liquids. Angew. Chem., Int. Ed. 2011, 50, 8683-8687.

(5) Migowski, P.; Machado, G.; Texeira, S. R.; Alves, M. C. M.; Morais, J.; Traverse, A.; Dupont, J. Synthesis and Characterization of Nickel Nanoparticles Dispersed in Imidazolium Ionic Liquids. Phys. Chem. Chem. Phys. 2007, 9, 4814-4821.

(6) Migowski, P.; Zanchet, D.; Machado, G.; Gelesky, M. A.; Teixeira, S. R.; Dupont, J. Nanostructures in Ionic Liquids: Correlation of Iridium Nanoparticles' Size and Shape With Imidazolium Salts' Structural Organization and Catalytic Properties. Phys. Chem. Chem. Phys. 2010, 12, 6826-6833.

(7) Gutel, T.; Santini, C. C.; Philippot, K.; Padua, A.; Pelzer, K.; Chaudret, B.; Chauvin, Y.; Basset, J. M. Organized 3D-Alkyl Imidazolium Ionic Liquids Could Be Used to Control the Size of In Situ Generated Ruthenium Nanoparticles? J. Mater. Chem. 2009, 19, 3624-3631.

(8) Redel, E.; Thomann, R.; Janiak, C. First Correlation of Nanoparticle Size-Dependent Formation with the Ionic Liquid Anion Molecular Volume. Inorg. Chem. 2008, 47, 14-16.

(9) Redel, E.; Thomann, R.; Janiak, C. Use of Ionic Liquids (ILs) for the IL-Anion Size-Dependent Formation of $\mathrm{Cr}$, Mo and $\mathrm{W}$ Nanoparticles From Metal Carbonyl $\mathrm{M}(\mathrm{CO})_{6}$ Precursors. Chem. Commun. 2008, 1789-1791.

(10) Julis, J.; Hölscher, M.; Leitner, W. Selective Hydrogenation of Biomass Derived Substrates Using Ionic Liquid-Stabilized Ruthenium Nanoparticles. Green Chem. 2010, 12, 1634-1639.

(11) Luska, K. L.; Moores, A. Ruthenium Nanoparticle Catalysts Stabilized in Phosphonium and Imidazolium Ionic Liquids: Dependence of Catalyst Stability and Activity on the Ionicity of the Ionic Liquid. Green Chem. 2012, 14, 1736-1742.

(12) Prechtl, M. H. G.; Scariot, M.; Scholten, J. D.; Machado, G.; Teixeira, S. R.; Dupont, J. Nanoscale $\mathrm{Ru}(0)$ Particles: Arene Hydrogenation Catalysts in Imidazolium Ionic Liquids. Inorg. Chem. 2008, 47, 8995-9001.

(13) Luska, K. L.; Moores, A. Functionalized Ionic Liquids for the Synthesis of Metal Nanoparticles and their Application in Catalysis. Chem CatChem 2012, 4, 1534-1546.

(14) Zhao, D. B.; Fei, Z. F.; Geldbach, T. J.; Scopelliti, R.; Dyson, P. J. Nitrile-Functionalized Pyridinium Ionic Liquids: Synthesis, Characterization, and their Application in Carbon-Carbon Coupling Reactions. J. Am. Chem. Soc. 2004, 126, 15876-15882.

(15) Fei, Z. F.; Zhao, D. B.; Pieraccini, D.; Ang, W. H.; Geldbach, T. J.; Scopelliti, R.; Chiappe, C.; Dyson, P. J. Development of NitrileFunctionalized Ionic Liquids for $\mathrm{C}-\mathrm{C}$ Coupling Reactions: Implication of Carbene and Nanoparticle Catalysts. Organometallics 2007, 26, 1588-1598.

(16) Cui, Y. G.; Biondi, I.; Chaubey, M.; Yang, X.; Fei, Z. F.; Scopelliti, R.; Hartinger, C. G.; Li, Y. D.; Chiappe, C.; Dyson, P. A Remarkable Anion Effect on Palladium Nanoparticle Formation and 
Stabilization in Hydroxyl-Functionalized Ionic Liquids. Phys. Chem. Chem. Phys. 2010, 12, 1834-1841.

(17) Konnerth, H.; Prechtl, M. H. G. Selective Partial Hydrogenation of Alkynes to ( $Z$ )-Alkenes With Ionic Liquid-Doped Nickel Nanocatalysts at Near Ambient Conditions. Chem. Commun. 2016, 52, 9129-9132.

(18) Yang, X.; Yan, N.; Fei, Z. F.; Crespo-Quesada, R. M.; Laurenczy, G.; Kiwi-Minsker, L.; Kou, Y.; Li, Y. D.; Dyson, P. J. Biphasic Hydrogenation Over PVP Stabilized Rh Nanoparticles in Hydroxyl Functionalized Ionic Liquids. Inorg. Chem. 2008, 47, 74447446.

(19) Luska, K. L.; Moores, A. Improved Stability and Catalytic Activity of Palladium Nanoparticle Catalysts using PhosphineFunctionalized Imidazolium Ionic Liquids. Adv. Synth. Catal. 2011, $353,3167-3177$.

(20) Stratton, S. A.; Luska, K. L.; Moores, A. Rhodium Nanoparticles Stabilized With Phosphine Functionalized Imidazolium Ionic Liquids as Recyclable Arene Hydrogenation Catalysts. Catal. Today 2012, 183, 96-100.

(21) Dykeman, R. R.; Yan, N.; Scopelliti, R.; Dyson, P. Enhanced Rate of Arene Hydrogenation with Imidazolium Functionalized Bipyridine Stabilized Rhodium Nanoparticle Catalysts. Inorg. Chem. 2011, 50, 717-719.

(22) Dykeman, R. R.; Yuan, Y.; Yan, N.; Asakura, H.; Teramura, K.; Tanaka, T.; Dyson, P. J. Rational Design of a Molecular NanocatalystStabilizer that Enhances both Catalytic Activity and Nanoparticle Stability. ChemCatChem 2012, 4, 1907-1910.

(23) Winterle, S.; Liauw, M. A. Katalytische Umsetzung von Cellobiose. Chem. Ing. Tech. 2010, 82, 1211-1214.

(24) Yan, N.; Yuan, Y. A.; Dykeman, R.; Kou, Y. A.; Dyson, P. J. Hydrodeoxygenation of Lignin-Derived Phenols Into Alkanes by Using Nanoparticle Catalysts Combined With Brønsted Acidic Ionic Liquids. Angew. Chem., Int. Ed. 2010, 49, 5549-5553.

(25) Julis, J.; Leitner, W. Synthesis of 1-Octanol and 1,1-Dioctyl Ether From Biomass-Derived Platform Chemicals. Angew. Chem., Int. Ed. 2012, 51, 8615-8619.

(26) Qadir, M. I.; Weilhard, A.; Fernandes, J. A.; de Pedro, I.; Vieira, B.; Waerenborgh, J. C.; Dupont, J. Selective Carbon Dioxide Hydrogenation Driven by Ferromagnetic RuFe Nanoparticles in Ionic Liquids. ACS Catal. 2018, 8, 1621-1627.

(27) Fehrmann, R.; Riisager, A.; Haumann, M. Supported Ionic Liquids: Fundamentals and Applications; Wiley-VCH: Weinheim, Germany, 2014

(28) Xin, B. W.; Hao, J. C. Imidazolium-Based Ionic Liquids Grafted on Solid Surfaces. Chem. Soc. Rev. 2014, 43, 7171-7187.

(29) Migowski, P.; Luska, K. L.; Leitner, W. In Nanocatalysis in Ionic Liquids; Prechtl, M. H. G., Ed.; Wiley VCH: Weinheim, Germany, 2016

(30) Luska, K. L.; Migowski, P.; El Sayed, S.; Leitner, W. Synergistic Interaction within Bifunctional Ruthenium Nanoparticle/SILP Catalysts for the Selective Hydrodeoxygenation of Phenols. Angew. Chem., Int. Ed. 2015, 54, 15750-15755.

(31) El Sayed, S.; Bordet, A.; Weidenthaler, C.; Hetaba, W.; Luska, K. L.; Leitner, W. Selective Hydrogenation of Benzofurans Using Ruthenium Nanoparticles in Lewis Acid-Modified RutheniumSupported Ionic Liquid Phases. ACS Catal. 2020, 10, 2124-2130.

(32) Luza, L.; Rambor, C. P.; Gual, A.; Bernardi, F.; Domingos, J. B.; Grehl, T.; Bruner, P.; Dupont, J. Catalytically Active Membranelike Devices: Ionic Liquid Hybrid Organosilicas Decorated with Palladium Nanoparticles. ACS Catal. 2016, 6, 6478-6486.

(33) Ding, S.; Guo, Y.; Hulsey, M. J.; Zhang, B.; Asakura, H.; Liu, L.; Han, Y.; Gao, M.; Hasegawa, J.-y.; Qiao, B.; Zhang, T.; Yan, N. Electrostatic Stabilization of Single-Atom Catalysts by Ionic Liquids. Chem 2019, 5, 3207-3219.

(34) Gai, H.; Zhong, C.; Liu, X.; Qiao, L.; Zhang, X.; Xiao, M.; Song, H. Poly(ionic liquid)-supported gold and ruthenium nanoparticles toward the catalytic wet air oxidation of ammonia to nitrogen under mild conditions. Appl. Catal., B 2019, 258, 117972.
(35) Luska, K. L.; Julis, J.; Stavitski, E.; Zakharov, D. N.; Adams, A.; Leitner, W. Bifunctional Nanoparticle-SILP Catalysts (NPs@SILP) for the Selective Deoxygenation of Biomass Substrates. Chem. Sci. 2014, 5, 4895-4905.

(36) Luska, K. L.; Bordet, A.; Tricard, S.; Sinev, I.; Grunert, W.; Chaudret, B.; Leitner, W. Enhancing the Catalytic Properties of Ruthenium Nanoparticle-SILP Catalysts by Dilution with Iron. ACS Catal. 2016, 6, 3719-3726.

(37) Offner-Marko, L.; Bordet, A.; Moos, G.; Tricard, S.; Rengshausen, S.; Chaudret, B.; Luska, K. L.; Leitner, W. Bimetallic Nanoparticles in Supported Ionic Liquid Phases as Multifunctional Catalysts for the Selective Hydrodeoxygenation of Aromatic Substrates. Angew. Chem., Int. Ed. 2018, 57, 12721-12726.

(38) Rengshausen, S.; Etscheidt, F.; Großkurth, J.; Luska, K. L.; Bordet, A.; Leitner, W. Catalytic Hydrogenolysis of Substituted Diaryl Ethers by Using Ruthenium Nanoparticles on an Acidic Supported Ionic Liquid Phase (Ru@SILP-SO $\left.{ }_{3} \mathrm{H}\right)$. Synlett 2019, 30, 405-412.

(39) Qadir, M. I.; Castegnaro, M. V.; Selau, F. F.; Samperi, M.; Fernandes, J. A.; Morais, J.; Dupont, J. Catalytic Semi-Water-Gas Shift Reaction: A Simple Green Path to Formic Acid Fuel. ChemSusChem 2020, 13, 1817-1824.

(40) Moos, G.; Emondts, M.; Bordet, A.; Leitner, W. Selective Hydrogenation and Hydrodeoxygenation of Aromatic Ketones to Cyclohexane Derivatives Using a Rh@SILP Catalyst. Angew. Chem., Int. Ed. 2020, 59, 11977-11983.

(41) Goclik, L.; Offner-Marko, L.; Bordet, A.; Leitner, W. Selective Hydrodeoxygenation of Hydroxyacetophenones to Ethyl-Substituted Phenol Derivatives Using a FeRu@SILP Catalyst. Chem. Commun. 2020, 56, 9509-9512.

(42) Cao, Y.; Mu, T. Comprehensive Investigation on the Thermal Stability of 66 Ionic Liquids by Thermogravimetric Analysis. Ind. Eng. Chem. Res. 2014, 53, 8651-8664.

(43) Babucci, M.; Akcay, A.; Balci, V.; Uzun, A. Thermal Stability Limits of Imidazolium Ionic Liquids Immobilized on Metal-Oxides. Langmuir 2015, 31, 9163-9176.

(44) Leitner, W.; Klankermayer, J.; Pischinger, S.; Pitsch, H.; KohseHöinghaus, K. Advanced Biofuels and Beyond: Chemistry Solutions for Propulsion and Production. Angew. Chem., Int. Ed. 2017, 56, $5412-5452$

(45) Hardacre, C.; Parvulescu, V. Catalysis in Ionic Liquids From Catalyst Synthesis to Application; The Royal Society of Chemistry: Cambridge, UK, 2014.

(46) Ye, L.; Lin, H.; Zhou, H.; Yuan, Y. Support and Size Effects of Ruthenium Catalysts with a Chiral Modifier for Asymmetric Hydrogenation of Aromatic Ketones. J. Phys. Chem. C 2010, 114, 19752-19760.

(47) Hansen, T. W.; DeLaRiva, A. T.; Challa, S. R.; Datye, A. K. Sintering of Catalytic Nanoparticles: Particle Migration or Ostwald Ripening? Acc. Chem. Res. 2013, 46, 1720-1730.

(48) Campbell, C. T.; Parker, S. C.; Starr, D. E. The Effect of SizeDependent Nanoparticle Energetics on Catalyst Sintering. Science 2002, 298, 811-814. 